\title{
Uniportal Video-assisted Thoracoscopic Bronchial Sleeve Lobecto- My in Five Patients
}

\author{
Zhi-liang $\mathrm{Hu}^{\mathrm{a}}$, Zhun $\mathrm{He}^{\mathrm{a}}$, Bo Jiang ${ }^{\mathrm{a} *}$, Zhen $\mathrm{Li}^{\mathrm{a}}$, Tao Zhang ${ }^{\mathrm{a}}$ \\ ${ }^{a}$ Department of Thoracic Surgery, The Affiliated Hospital of Jining Medical University, Jining 272000, People's Republic of China.
}

\section{Abstract}

Objective: To investigate the clinical efficacy and value of uniportal video-assisted thoracoscopic bronchial sleeve lobectomy (BSL) in the treatment of central lung cancer.

Methods: The clinical data of five patients who underwent uniportal video-assisted thoracoscopic BSL at our hospital from October 2014 to September 2016 were retrospectively analyzed.

Results: The BSL procedure was successful in all five cases. The average operation time was $254 \mathrm{~min}$, and the mean time to complete the anastomosis was $168 \mathrm{~min}$. The average blood loss was $116 \mathrm{ml}$, and the mean number of lymph node dissections was 16.6 /case. The average intubation time was $5 \mathrm{~d}$, and the total postoperative drainage volume was $732 \mathrm{ml}$. The mean VAS score was 2.86, and the average postoperative hospital stay was $9.2 \mathrm{~d}$. All patients were followed up for 3-19 months, and all of them survived without recurrence or metastasis.

Conclusion: Uniportal video-assisted thoracoscopic BSL was found to be safe, reliable, and minimally invasive.

Keywords: lung cancer; bronchial sleeve lobectomy; video-assisted thoracoscopic surgery; anastomosis

\section{INTRODUCTION}

Lung cancer, also known as bronchogenic carcinoma, has the highest incidence and mortality in China ${ }^{[1]}$. The most common treatment for lung cancer is traditional thoracotomy. This method has rapid effects and can improve patients' survival rates ${ }^{[2]}$. However, traditional thoracotomy requires a large incision, and patients often experience severe pain postoperatively ${ }^{[3]}$. In addition, traditional thoracotomy can reduce lung function, which has a serious impact on quality of life ${ }^{[4]}$. Therefore, it is important to identify an effective treatment method to improve the quality of life and prognosis of patients following this procedure.

The goal of lung cancer resection is to remove as much of the tumors as possible while sparing healthy lung tissue ${ }^{[5]}$. A sleeve lobectomy fully reflects this principle; patients who undergo sleeve lobectomy report better quality of life and greater long-term survival compared with those who receive a pneumonectomy ${ }^{[6]}$. In addition, the surgical and long-term mortality rates for sleeve lobectomy are low ${ }^{[7]}$. However, due to the problem of bronchial reconstruction, uniportal vid-

\footnotetext{
*Corresponding author: Bo Jiang

Mailing address: Department of Thoracic Surgery, The Affiliated Hospital of Jining Medical University. No. 89 Guhuai Street, Jining 272000, Shandong, People's Republic of China. E-mail: 13563755772@163.com

Received: 25 July 2018 Accepted: 25 September 2018
}

eo-assisted thoracoscopic bronchial sleeve lobectomy (BSL) is considered a difficult and high-risk operation. At present, few studies have been published on this procedure. Five patients received uniportal video-assisted thoracoscopic BSL in our hospital from October 2014 to September 2016, and all of them obtained good results.

\section{CLINICAL DATA AND METHODS \\ Clinical data}

The clinical data of five patients who underwent uniportal video-assisted thoracoscopic BSL at the Affiliated Hospital of Jining Medical University from October 2014 to September 2016 were retrospectively analyzed. There were four males and one female with a mean age of 57.4 years (range: 47-65 years). Preoperative symptoms were as follows: two cases of irritable cough, two cases of cough and hemoptysis, and two cases of cough and fever. The diseased lung regions were located in the left upper lobe in one case, the right upper lobe in three cases, and the right middle lobe in one case; all these lesions were peripheral and solitary lesions. All patients were examined by chest computed tomography (CT), fiberoptic bronchoscopy, brain CT, and abdominal ultrasound to identify any metastatic lesions before the surgery. Inclusion criteria were as follows: central lung cancer; a lesion that involved the opening of the bronchial lobe or was adjacent to the main bronchial wall with normal distal 
lung tissue; a clinical stage within III A stage; and preoperative pulmonary insufficiency or an inability to tolerate pneumonectomy. The results of preoperative pathological examinations are shown in Table 1.

\section{Operation methods}

All patients received double lumen endotracheal intubation combined with intravenous anesthesia. A 4-cm incision was made as an observation portal at the fourth intercostal on the anterior axillary line. The operation was performed by first cleaning the lymph nodes and then removing the pulmonary lobes. The right upper lobe sleeve lobectomy procedure was as follows: The inferior pulmonary ligament was opened using electrocautery then cut from the pleura to the arcus venae azygos. Group 7, 8, and 9 lymph nodes were cleared. The anterior pleura of the lung was opened and re-flexed. Group 10 and the right group 2, 3 , and 4 lymph nodes were subsequently cleared. The left group 4 and 5 lymph nodes were also cleared. The tunnel method was used to open up poorly developed horizontal or oblique fractures. The superior pulmonary vein and the middle lobe vein were all dissociated and cut. The group 11 lymph node was removed after upturning the distal pulmonary vein. Then, each pulmonary artery was exposed and closed using Endo-GIA. The separation and cut order of the arteriovenous was determined by observing the intraoperative conditions. Next, the exposed pulmonary bronchus opening and the bilateral main bronchus were separated, and the bronchial was cut off at $0.5 \mathrm{~cm}$ from the bronchial opening with a sharp blade and scissors. Finally, the diseased lung was removed.

The diseased lung and lymph nodes were sent for pathological examination. The bronchial stump (surgical margins) was sent for intraoperative frozen pathological examination. The bronchial anastomosis was reconstructed until the surgical margins were negative. In the process of anastomosis, the incision was trimmed to achieve the same caliber as that of the bronchus at both ends. Double-armed 3-0 Prolene suture was used in continuous suture. The first needle penetrated the distal bronchus to the inside, and then the needle was inserted from the proximal bronchial lumen to the outside. In the sewing process, the suture was not tightened until the needles rendezvoused. Finally, the surgeon ensured that the bronchial anastomosis was free of air before inserting the chest drain-

age tube and closing the incision.

\section{Index observation}

The following indexes were analyzed following the operation: the number of lymph node dissections, post- operative pathology and stage, operation time, bronchial anastomosis time, intraoperative blood loss amount, total postoperative drainage volume, intubation time (remove drainage tube until draining fluid less $<150$ $\mathrm{ml} / \mathrm{d}$ ), postoperative hospital stay length, visual analogue scale (VAS) pain score, complications, and follow-up time. The patient's pain level was assessed daily (1-5 days) using the VAS after surgery. Intraoperative blood loss = blood volume in a suction device + gauze blood volume (20 ml/each piece of gauze).

\section{RESULTS}

The operation was successful in five cases, and no severe complications or deaths occurred during the perioperative period. The patients were admitted to the two grades intensive care unit (ICU) after the operation and then transferred to the general ward after two days of observation. The average operation time was $254 \mathrm{~min}$, and the average time required to complete the anastomosis was $168 \mathrm{~min}$. The average blood loss was $116 \mathrm{ml}$, and the average number of lymph node dissections was 16.6/case. The mean intubation time was $5 \mathrm{~d}$, and the total postoperative drainage volume was $732 \mathrm{ml}$. The average VAS score was 2.86, and the mean length of the postoperative hospital stay was $9.2 \mathrm{~d}$. Postoperative complications were as follows: one case had atelectasis, and another case developed pneumonia. The patients recovered after treatment with nebulization, sputum excretion, balloon blowing, and anti-infection measures. Internal medicine chemotherapy was performed in two cases after the procedure. All patients were followed up for 3-19 months, and all survived without recurrence or metastasis (Table 2).

\section{DISCUSSION}

Video-assisted thoracoscopic surgery (VATS) has become the first choice for the radical resection of lung cancer. Due to advancements in technology, the number of required ports has been reduced, and the technical difficulty has also improved. Moreover, some highly difficult techniques in traditional thoracotomy have gradually been mastered. Thoracoscopic BSL is one type of VATS. Santambrogio et al. ${ }^{[8]}$ reported the world's first thoracoscopic BSL in 2002, and other relevant reports appeared ${ }^{[9-11]}$. Th'oracoscopic BSL has been proven to be a safe and effective procedure that achieves the desired effect ${ }^{[12]}$. In 2013, Gonzalez et al. ${ }^{[13]}$ completed uniportal video-assisted thoracoscopic BSL. Lung cancer patients who were candidates for thoracoscopic BSL accounted for 5-13\% of all surgeries ${ }^{[14]}$, which expanded the indications for VATS in lung cancer patients. Some patients with central lung cancer 
can benefit from the operation, especially those with an advanced age and low cardiorespiratory function.

The thoracoscopic BSL procedure is complex and difficult. It requires a skilled endoscopic lobectomy and suture technique ${ }^{[15]}$, so it has developed slowly. Additionally, there is no uniform standard for this procedure's indications and method. Some experts have proposed their own suggestions ${ }^{[16,17]}$, which can be summed up as follows: patients whose peripheral vessels and organs are not significantly involved may undergo thoracoscopic BSL to remove the diseased lung and lymph nodes and reconstruct the airway. In the current study, all five patients were selected according to the above principles. At present, thoracoscopic BSL usually involves a multi-port technique. However, we used a single-port procedure as follows.

The uniportal video-assisted thoracoscopic BSL is difficult to carry out. The length of a single incision that serves as a port is approximately $4-5 \mathrm{~cm}$. This port must accommodate many instruments, such as a mirror rod, aspirator, and elastic separating plier. Thus, the space left over for the operation is quite narrow. The biggest difficulty is that the line of sight and the operating direction are essentially located on the same axis, which restricts the instruments and affects the operation. Moreover, the cutter stapler is difficult to place due to space and direction constraints. Even if an Endo-GIA stapler is used, the procedure is still complex. Because of these inherent characteristics, the difficulty level of uniportal video-assisted thoracoscopic BSL is increased, which presents a challenge for many doctors.

Forming an anastomosis of the bronchus using a single port is the main difficulty of this procedure. At present, there are a variety of anastomosis techniques, and each has its advantages and disadvantages. Akiba et al. ${ }^{[18]}$ used interrupted suture with absorbable sutures. Lin et al. ${ }^{[19]}$ used a running suture with 3-0 Prolene. Li et al.
${ }^{[15]}$ suggested a combination of discontinuous nodules and continuous suture. In the present study, the anastomosis was performed using continuous suture with 3-0 Prolene. The method is simple, and the experience can be summarized as follows: (1) To ensure a safe distance, the free distance between the incisal edge of the main bronchus should be no larger than 0.5-1.0 $\mathrm{cm}$ to avoid affecting the blood supply, obstruction, or anastomotic healing. (2) The surgeon should have extensive experience with laparoscopic procedures and excellent suturing skills under laparoscopy. The assistants should also have good coordination. (3) It is not necessary to strain the sutures while suturing. Although it will increase the chances of twisted wires, it is beneficial to adjust the needle angle. This is also the main way to solve the problem of multi-needle direction in single-hole laparoscopy. If the suture is strained at the beginning, the next needle angle will be difficult, and the difficulty and length of the operation will also increase. (4) The angle of the needle is difficult to control with a single operating hole; we solved the problem of needle insertion by pulling and pressing, adjusting the direction of needle holding and straightening the needle. (5) To place the corresponding sutures, the membranous portion and the cartilaginous section of the bronchus should be distinguished. Additionally, to avoid wrinkles, twisting, or chinking after the anastomosis, the ends of the incisal margin should be close to each other. (6) Any sputum and blood located in the bronchus should be completely removed before beginning the anastomosis. Prior to extubation, sputum should be removed once more to expand the lung and reduce the occurrence of postoperative pneumonia and atelectasis. (7) To lower the risk of chest infection, aseptic techniques are used during the operation; disinfection should be performed both before and after the anastomosis, and the chest must be flushed repeatedly before closure. Bronchial anastomosis is the key

Table 1 General data of patients

\begin{tabular}{|c|c|c|c|c|c|c|c|c|}
\hline No. & Gender & r Age & $\begin{array}{l}\text { Preoperative } \\
\text { symptoms }\end{array}$ & $\begin{array}{l}\text { Lesion } \\
\operatorname{size}(\mathrm{cm})\end{array}$ & Complications & D reg. & $\begin{array}{l}\text { Preoperative } \\
\text { pathology }\end{array}$ & $\begin{array}{l}\text { Preoperative } \\
\text { stage }\end{array}$ \\
\hline 1 & Male & 56 & Cough and hemoptysis & $2.3 \times 2.1 \times 1.8$ & Primary hypertension & Right upper lobe & SCC & II B \\
\hline 2 & Male & 47 & Cough & $3.0 \times 2.5 \times 2.2$ & $\begin{array}{l}\text { Chronic bronchitis } \\
\text { and emphysema }\end{array}$ & Right upper lobe & SCC & II B \\
\hline 3 & Male & 65 & Cough & $2.2 \times 2.0 \times 1.7$ & Chronic bronchitis & Right middle lobe & SCC & III A \\
\hline 4 & Female & 59 & Cough and fever & $3.1 \times 2.7 \times 2.4$ & Diabetes & Right upper lobe & Adenocarcinoma & II A \\
\hline 5 & Male & 60 & Cough and hemoptysis & $3.0 \times 2.8 \times 2.5$ & $\begin{array}{l}\text { Primary hypertension } \\
\text { and and coronary } \\
\text { atherosclerotic heart } \\
\text { disease }\end{array}$ & Left upper lobe & SCC & II B \\
\hline
\end{tabular}


Table 2 The intraoperative and postoperative condition of patients

\begin{tabular}{|c|c|c|c|c|c|c|c|c|c|}
\hline No. & \multicolumn{2}{|l|}{ Operative type } & $\begin{array}{l}\text { Number } \\
\text { of LND }\end{array}$ & \multicolumn{2}{|c|}{$\begin{array}{l}\text { Postoperative } \\
\text { pathology }\end{array}$} & \multicolumn{2}{|c|}{$\begin{array}{l}\text { Postoperative } \\
\text { stage }\end{array}$} & $\begin{array}{l}\text { Operation } \\
\text { time (min) }\end{array}$ & $\begin{array}{l}\text { Anastomotic } \\
\text { time (min) }\end{array}$ \\
\hline 1 & \multicolumn{2}{|c|}{ Right upper lobe BSL } & 19 & SCC & & \multicolumn{2}{|c|}{$\mathrm{T} 2 \mathrm{~N} 2 \mathrm{M} 0$} & 310 & 260 \\
\hline 2 & \multicolumn{2}{|c|}{ Right upper lobe BSL } & 22 & Adenosquamous & carcinoma & \multicolumn{2}{|c|}{$\mathrm{T} 2 \mathrm{~N} 2 \mathrm{M} 0$} & 260 & 180 \\
\hline 3 & \multicolumn{2}{|c|}{ Right middle lobe BSL } & 13 & SCC & & \multicolumn{2}{|c|}{ T2N0M0 } & 220 & 110 \\
\hline 4 & \multicolumn{2}{|c|}{ Right upper lobe BSL } & 17 & Adenocarcinoma & & \multicolumn{2}{|c|}{ T2N0M0 } & 200 & 90 \\
\hline 5 & \multicolumn{2}{|c|}{ Left upper lobe BSL } & 12 & \multicolumn{2}{|c|}{ SCC } & \multicolumn{2}{|c|}{ T2N1M0 } & 280 & 200 \\
\hline \multicolumn{3}{|l|}{ Mean Value } & \multicolumn{5}{|l|}{16.6} & 254 & 168 \\
\hline No. & $\begin{array}{l}\text { Intraoperative } \\
\text { blood loss }(\mathrm{ml})\end{array}$ & $\begin{array}{l}\text { Tota } \\
\text { drair }\end{array}$ & $\begin{array}{l}\text { ostoperative } \\
\text { ge volume }(\mathrm{ml})\end{array}$ & $\begin{array}{l}\text { Intubation } \\
\text { time (d) }\end{array}$ & $\begin{array}{l}\text { Postoper } \\
\text { hospital s }\end{array}$ & $\begin{array}{l}\text { tive } \\
\text { tay (d) }\end{array}$ & $\begin{array}{l}\text { VAS pain } \\
\text { score } *\end{array}$ & Complications & $\begin{array}{l}\text { Follow-up } \\
\text { time (month) }\end{array}$ \\
\hline 1 & 100 & 600 & & 5 & 9 & & 2.4 & - & 19 \\
\hline 2 & 120 & 1260 & & 7 & 12 & & 3.7 & $\begin{array}{l}\text { Middle lobe } \\
\text { atelectasis }\end{array}$ & 17 \\
\hline 3 & 90 & 440 & & 4 & 7 & & 2.6 & - & 10 \\
\hline 4 & 110 & 560 & & 4 & 8 & & 2.5 & $\begin{array}{l}\text { Lower lobe } \\
\text { inflammation }\end{array}$ & 8 \\
\hline 5 & 160 & 800 & & 5 & 10 & & 3.1 & - & 3 \\
\hline Mean value & 116 & 732 & & 5 & 9.2 & & 2.86 & & 11.4 \\
\hline
\end{tabular}

Abbreviations: BSL=bronchial sleeve lobectomy; LND=lymph node dissection; SCC=squamous cell carcinoma; VAS=visual analogue scale.

*Average score of VAS at 1 to 5 days after surgery.

link after sleeve lobectomy and also the main factor that limits a short operation time. During our procedures, the anastomotic time ranged from 90-260 min, and the average anastomotic time each patient was $168 \mathrm{~min}$. The time spent creating the anastomosis represented $66 \%$ of the total operative time. Therefore, the time required for bronchial anastomosis is also the node that has the greatest impact on how minimally invasive a procedure is: this aspect needs further improvement.

Additionally, we used the whole group cleaning method to remove group 2, 3, 4, and 7 lymph nodes and achieved an acceptable cleaning effect. We used the hollow out method to clean the group 10 and 11 lymph nodes and also freed the bronchus and vessels during the cleaning. In our procedures, more than five groups of lymph nodes were removed in each case, and the average number of lymph nodes per patient was 16.6, which exceeded the minimum requirements of Ludwig et al. (11-16 lymph nodes) ${ }^{[20]}$. Thus, combined with the observation of the treatment effects of single-hole thoracoscopic surgery in recent years, lymph node dissection could meet the radical requirements of lung cancer in the present operation.

The complications that result from a sleeve lobectomy for lung cancer are similar to those of a conventional lobectomy procedure but are superior to those following a pneumonectomy ${ }^{[21]}$. Pulmonary infection and atelectasis are common complications after this type of surgery. In this study, one case developed pneumonia, and one other case experienced atelectasis. All patients were cured in a short period of time after treatment with sputum excretion and other in measures. Remarkably, anastomotic leakage was the most dangerous complication of sleeve lobectomy. We believe that the major measures taken during this procedure to prevent anastomotic leakage can ensure the blood supply at both ends of the bronchial anastomosis, make the incisal margin fit, and reduce contamination. Moreover, prior studies have revealed that the use of biological protein glue and also the covering of the pleura or pericardium could reduce the occurrence of anastomotic leakage ${ }^{[22]}$. None of our patients experienced anastomotic leakage despite the fact that we did not take these measures. As expected, the CT reconstruction was performed at one month postoperatively, and no obvious anastomotic stenosis was found.

The mortality rate of sleeve lobectomy is reportedly $2-6 \%$, which is lower than the rate for total pneumonectomy; the five-year survival rate is $38.6-57 \%$ and therefore is significantly higher than that of a pneumonectomy ${ }^{[23]}$. In this study, all patients were still living within 3-19 months of follow-up. However, due to the short follow-up time, the long-term survival rate still needs further observation.

In our study, we observed the total operation time, amount of bleeding, postoperative drainage volume, intubation time, length of hospital stay, and VAS score. We found that the initial surgery time was long, but the operation time gradually shortened. Therefore, it 
can be concluded that the operation time for uniportal video-assisted thoracoscopic BSL will not be short but can be reduced with surgical proficiency and the accumulation of experience. Additionally, there were no significant differences in the amount of bleeding, postoperative drainage volume, intubation time, and length of hospital stay. The single-hole sleeve lobectomy technique may also reduce postoperative pain in patients compared to other procedures that require more incisions. As a result, uniportal video-assisted thoracoscopic BSL is safe, reliable, and minimally invasive.

Since Gonzalez et al. ${ }^{[24]}$ first reported a case using single-port video-assisted thoracoscopic lobectomy, the single-port thoracoscopic technology has developed rapidly and has become an important technical method for the advancement of thoracoscopy. It has the advantages of being minimally invasive, having only moderate technical difficulty, and being a good solution for complicated situations. At present, uniportal video-assisted thoracoscopic BSL is less. We hope that our work will contribute to further development of this technology.

\section{REFERENCES}

1. Chen, W., Zheng, R., Zhang, S., Zhao, P., Zeng, H., Zou, X., and He, J. (2014) Annual report on status of cancer in China, 2010. Chin J Cancer Res 26, 48-58

2. Andrews, W. G., and Paul, S. (2016) Techniques of video-assisted thoracoscopic surgery lobectomy and critical review of published data. Future Oncol 12, 31-33

3. Lou, W., Zhan, X., Xiang, X., and Guan, W. (2012) Effect of VATS wedge resection and mediastinal lymph node sampling in elderly patients with early peripheral lung cancer. Zhongguo fei ai za zhi 15, 49-51

4. Panda, S. S., Agarwala, S., Kabra, S. K., and Bhatnagar, V. (2014) A survey of pulmonary function abnormalities following thoracotomy. Indian J Pediatr 81, 660-664

5. Zeng, L., Kuang, Y., Wu, J., Lin, Q., Yin, B., Wang, D., Wang, Z., Huang, J., and He, Z. (2002) Carinal resection and bronchial sleeve lobectomy in the treatment of central lung cancer: A report of 105 cases. Zhongguo fei ai za zhi 5, 414-415

6. D'Andrilli, A., Maurizi, G., Andreetti, C., Ciccone, A. M., Ibrahim, M., Piraino, A., Mariotta, S., Venuta, F., and Rendina, E. A. (2016) Sleeve Lobectomy Versus Standard Lobectomy for Lung Cancer: Functional and Oncologic Evaluation. Ann Thorac Surg 101, 1936-1942

7. Shi, W., Wei, Z., Sun, H., and Shao, Y. (2012) Sleeve lobectomy versus pneumonectomy for non-small cell lung cancer: a meta-analysis. World J Surg Oncol 10, 265-274

8. Santambrogio, L., Cioffi, U., De, S. M., Rosso, L., Ferrero, S., and Giunta, A. (2002) Video-assisted sleeve lobectomy for mucoepidermoid carcinoma of the left lower lobar bronchus: a case report. Chest 121, 635-636

9. Liu, K., Jin, C., Tian, H., and Shen, W. (2013) Total video-assisted thoracic surgery sleeve lobectomy: suture by both hands. The Thoracic and cardiovascular surgeon reports 2, 43-45

10. Zhou, S., Pei, G., Han, Y., Yu, D., Song, X., Li, Y., Xiao, N., Liu, S., Liu, Z., and Xu, S. (2015) Sleeve lobectomy by video-assisted thoracic surgery versus thoracotomy for non-small cell lung cancer. Journal of cardiothoracic surgery 10, 116

11. Xiong, F., Wang, S., and Kai, J. (2014) Video-assisted thoracic surgery right sleeve lobectomy. Journal of thoracic disease 6, 1831-1833

12. Gonzalezrivas, D., Yang, Y., Stupnik, T., Sekhniaidze, D., Fernandez, R., Velasco, C., Zhu, Y., and Jiang, G. (2016) Uniportal video-assisted thoracoscopic bronchovascular, tracheal and carinal sleeve resections $\dagger$. Eur J Cardiothorac Surg 49, i6-16

13. Gonzalez-Rivas, D., Fernandez, R., Fieira, E., and Rellan, L. (2013) Uniportal video-assisted thoracoscopic bronchial sleeve lobectomy: first report. J Thorac Cardiovasc Surg 145, 1676-1677

14. Tedder, M., Anstadt, M. P., Tedder, S. D., and Lowe, J. E. (1992) Current morbidity, mortality, and survival after bronchoplastic procedures for malignancy. Ann Thorac Surg 54, 387-391

15. Li, Y., and Wang, J. (2013) Video-assisted thoracoscopic surgery sleeve lobectomy with bronchoplasty. World J Surg 37, 1661-1665

16. Ohata, K., Zhang, J., Ito, S., Yoshimura, T., Matsubara, Y., and Terada, Y. (2014) Thoracoscopic Bronchoplasty Using Continuous Sutures in Complete Monitor View. Ann Thorac Surg 98, 1132-1133

17. Yu, D., Han, Y., Zhou, S., Song, X., Li, Y., Xiao, N., and Liu, Z. (2014) Video-assisted thoracic bronchial sleeve lobectomy with bronchoplasty for treatment of lung cancer confined to a single lung lobe: a case series of Chinese patients. J Cardiothorac Surg 9, 1-6

18. Akiba, T., Marushima, H., Kawahara, H., Takagi, M., Hirano, J., Odaka, M., Nakanishi, K., Takeyama, H., Kobayashi, S., and Morikawa, T. (2010) Video-assisted thoracic surgery for patients with lung cancer and interstitial pneumonia. Ann Thorac Cardiovasc Surg 16, 236-241

19. Lin, J., Kang, M., Chen, S., Lin, J., Han, W., and Chen, M. (2015) Video-assisted thoracoscopic right upper lobe sleeve lobectomy combined with carinal resection and reconstruction. J Thorac Dis 7, 1861-1864

20. Ludwig, M. S., Goodman, M., Miller, D. L., and Johnstone, P. A. (2005) Postoperative survival and the number of lymph nodes sampled during resection of node-negative non-small cell lung cancer. Chest 128, 1545-1550

21. Pagã"S, P. B., Mordant, P., Renaud, S., Brouchet, L., Thomas, P. A., Dahan, M., and Bernard, A. (2017) Sleeve lobectomy may provide better outcomes than pneumo- 
nectomy for non-small cell lung cancer. A decade in a nationwide study. J Thorac Cardiovasc Surg 153, 184-195

22. Fadel, E., Yildizeli, B., Chapelier, A. R., Dicenta, I., Mussot, S., and Dartevelle, P. G. (2002) Sleeve lobectomy for bronchogenic cancers: factors affecting survival. Ann Thorac Surg 74, 858-859

23. Lee, E. S., Park, S. I., Kim, Y. H., Bae, C. H., Moon, H. W.,
Chun, M. S., and Kim, D. K. (2007) Comparison of operative mortality and complications between bronchoplastic lobectomy and pneumonectomy in lung cancer patients. J Korean Med Sci 22, 43-47

24. Gonzalez, D., Paradela, M., Garcia, J., and Dela, T. M. (2012) Single-port video-assisted thoracoscopic lobectomy. Interact Cardiovasc Thorac Surg 13, 539-540 